\title{
A AGENDA DE PESQUISA EVOLUCIONÁRIA DE NELSON E SEUS PONTOS DE CONTATO COM OS INSTITUCIONALISTAS
}

\author{
NELSON'S RESEARCH AGENDA AND ITS POINTS OF CONTACT WITH \\ INSTITUTIONALISTS
}

Rafaela Escobar Burger ${ }^{1}$

Silvio Antônio Ferraz Cario²

\section{RESUMO}

O objetivo desse trabalho é demonstrar a aproximação entre a abordagem evolucionária de Richard Nelson com a escola institucionalista. Com base no panorama institucionalista e evolucionário, o casamento entre as duas agendas de pesquisa é bastante viável. Isso pode ser observado no trabalho de Nelson e Sampat que, apesar da aparente diversidade na literatura sobre como as instituições são definidas, existe uma relação familiar, pelo menos em relação às intenções dos escritos. De forma explícita ou implícita, os autores sugerem que o conceito de "tecnologia social" seja útil para pensarmos mais coerentemente sobre as instituições, visto que envolve uma ampliação do modo como os economistas conceituam uma "atividade" econômica. Processos de busca, rotinas, seleção, aprendizado que cercam a atividade inovativa, ocorrem em um ambiente dinâmico, incerto e diversificado, podendo conferir distintas trajetórias. Nelson, um dos interlocutores dos neo-schumpeterianos, mesmo centrado em discutir a mudança técnica, considera importante o papel das instituições, uma vez que estas podem definir padrões ou trajetórias de desenvolvimento econômico distintos.

Palavras-chave: Institucionalistas; Evolucionários; Nelson; Tecnologia.

\section{ABSTRACT}

The aim of this paper is to demonstrate the rapprochement between Richard Nelson's evolutionary approach and the institutionalist school. Based on the institutionalist and evolutionary landscape, the marriage between the two research agendas is quite viable. This can be seen in the work of Nelson and Sampat that, despite the apparent diversity in the literature about how institutions are defined, there is a family relationship, at least with the intentions of the writings. Explicitly or implicitly, the authors suggest that the concept of "social technology" is useful for thinking more coherently about institutions, as it involves broadening the way economists conceptualize economic "activity." Search processes, routines, selection, learning that surround the innovative activity, occur in a dynamic, uncertain and diverse environment, and can give different trajectories. Nelson, one of the neo-Schumpeterian

\footnotetext{
${ }^{1}$ Doutoranda do Programa de Pós-Graduação em Administração -Universidade Federal de Santa Catarina. E-mail : rafaelaescobarburger@gmail.com

${ }^{2}$ Professor do Programa de Pós-Graduação em Administração e do Programa de Pós-Graduação em Economia. Universidade Federal de Santa Catarina. E-mail : fecario@yahoo.com.br
} 
interlocutors, even focused on discussing technical change, considers the role of institutions to be important, as they can define different patterns or trajectories of economic development.

Keywords: Institutionalists; Evolutionary; Nelson; Social Technology

JEL: B15; B52; O32

INTRODUÇÃO

Schumpeter foi um dos pioneiros no estudo da inovação - novas combinações - tratando-a como determinante do desenvolvimento econômico. Em sua visão, introduzir novos produtos, criar método produtivo e matérias primas, bem como adentrar novo mercado consumidor e organização industrial modificam e impulsionam o status quo existente no sistema econômico. As inovações transformam as estruturas econômicas nos termos de impactar a destruição criadora (o novo superando e se estabelecendo sobre 0 velho). Os seguidores hodiernos neoschumpeterianos/evolucionários (Nelson, Dosi, Lundvall,) - avançam no tratamento das ideias originárias de Schumpeter. Para explicar o desenvolvimento capitalista, a partir das inovações, esses seguidores introduzem novas categorias de análise, como processos de busca, rotina e seleção; paradigma e trajetória tecnológicas; mecanismos de aprendizagem; regime tecnológico, padrão setorial de inovação, sistema de inovação, entre outras.

No curso do desenvolvimento teórico-analítico neoschumpeteriano, alguns autores passam a incorporar elementos analíticos da escola institucionalista para explicar a mudança técnica. Ainda que a mudança técnica tenha seus fundamentos explicativos próprios, compreende-se a necessidade de introduzir outro campo teórico analítico proveniente do velho e do neoinstitucionalismo para explicar o processo inovativo. Nessa perspectiva, as contribuições teórico-analíticas de autores do velho institucionalismo, com destaque para Veblen, e dos neo-institucionalistas, em particular de Hodgson, são referências maiores para os neoschumpeterianos. Logo, estes introduzem, em seus escritos, categorias analíticas institucionalista, como: intenções, hábitos, cultura, valores, linguagem, condutas, rotinas, normas, regras, entre outras.

Um autor referência que procura desenvolver uma visão integrada de tais matrizes terórica-analiticas é Richard Nelson. Seus escritos, realizados de forma individual ou em parceria, evidenciam tal integração a partir dos conceitos de rotinas, tecnologias sociais, e sistema de inovação. Para Nelson (2006), o casamento entre as duas agendas de pesquisa é bastante viável, propondo, inicialmente, a incorporação das "rotinas" como conceito unificador. Na sequência, discute o conceito de "tecnologia social", como inerentemente vinculado às instituições e a uma teoria evolucionária de crescimento econômico. E, como elemento final, que impulsiona 0 desenvolvimento de uma nação, explicita o significado de "sistema de inovação".

Nesses termos, o presente artigo tem como objetivo demonstrar a aproximação entre a abordagem evolucionária de Richard Nelson com a escola institucionalista. Para tanto, visando esse objetivo, incorporam-se, nesta análise, trabalhos e artigos seminais dos principais autores da escola institucionalista, bem como os artigos e livros mais citados de Richard Nelson (alguns em parceria com outros autores). Além disso, outros trabalhos empíricos e teóricos de relevância para a academia foram utilizados de forma a apoiar a estrutura teórica pretendida. 
Estruturalmente, este artigo encontra-se organizado em cinco seções, sendo que, nesta primeira seção, traça-se o objetivo principal; na segunda, apresenta-se o panorama das concepções institucionalistas, em destaque as variáveis teóricas centrais do velho institucionalismo, da nova economia institucional e do neoinsticionalismo, que permitem contato com 0 tratamento evolucionário neoschumpeteriano; a terceira seção, dedica-se em apresentar a concepção teórica, elaborada por Richard Nelson, sobre rotinas, tecnologia social, crescimento econômico e sistema nacional de inovação; na quarta, busca-se fazer a aproximação teórica deste tratamento com a abordagem institucionalista; e, por fim, na quinta seção, fazem-se as considerações finais.

\section{PANORAMA INSTITUCIONAL E EVOLUCIONÁRIO}

Sophisticated scholars of technological advance always have understood the important role of institutional structures in supporting and molding efforts to advance technology. Thus, institutions play a central place in that role (NELSON; NELSON, 2002).

A abordagem institucionalista, com um núcleo teórico definido e nem sempre convergente entre suas três escolas - Velho Institucionalismo, Nova Economia Institucional e Neo-institucionalistas-, pela própria diversidade que as caracterizam, definem instituições de maneira heterogênea, (como hábitos ou normas, como regras ou formas institucionais ou como padrão de organização ou direitos de propriedade) (CONCEIÇÃO, 2002). Mesmo com esta aparente divergência, tal fato não invalida a contribuição teórica de cada abordagem. Pelo contrário, esta discrepância conceitual ao termo "instituições é, para Samuels (1995), o que constitui a própria fonte de riqueza do pensamento institucionalista. Cada conceito corresponde a uma abordagem, razão pela qual Conceição (2002) afirma que pensar ou conceber instituições sob um único enfoque é empobrecer seu campo analítico, que tem na interação sua mais relevante expressão teórica.

Mesmo com o amplo conceito causado pelas inúmeras definições, e que ainda se desdobram em outras inúmeras interpretações em relação às instituições, Pondé (2005, p. 123) destaca que o elemento essencial que caracteriza o que são instituições repousa na identificação de certo tipo de regularidade de comportamentos ou, parafraseando o autor, "algum tipo de estrutura subjacente que gera esta regularidade."

Com base nesse aspecto em comum, a linha teórica institucionalista é subdividida em três correntes: o Antigo Institucionalismo de Veblen, Commons e Mitchel, a Nova Economia Institucional de Coase, Williamson e North, e a corrente neoinstitucionalista com Geoffrey Hodgson, que reivindica sua filiação ao "velho" institucionalismo e uma grande proximidade com o evolucionismo (CONCEIÇÃO, 2008a).

Como precursor do legado institucionalista, Thorstein Veblen com o "velho" institucionalismo, apresenta as instituições como um conjunto de resultados provenientes da interação dos homens, sua forma de pensar e sua forma de produzir suas ações, ou seja, um padrão de ação coletiva da humanidade que é produzida a partir do processo histórico (CONCEIÇÃO, 2008a). Veblen (1898) e seu colega no velho institucionalismo, Mitchell (1910b), entendiam as instituições como hábitos mentais, no sentido de pensamentos predominantes que ganharam aceitação geral como normas de conduta. Um crítico da ciência econômica em busca de leis que 
regeriam a ordem natural da humanidade, Veblen ressaltava que a análise econômica deveria ser colocada como uma ciência da evolução, construindo uma teoria de processos (VEBLEN, 1898).

A partir do pensamento vlebeniano, destaca-se algumas categorias fundamentais que são basilares para a construção da teoria institucionalista: os instintos, os hábitos, as instituições propriamente ditas e a mudança institucional (MONASTERIO, 1998). Na visão de Hodgson (2001a), dentre as ideias centrais do institucionalismo destacam-se as instituições, os hábitos, as regras e sua evolução.

A diferença da visão Vebleriana para neoclássica, na perspectiva de Conceição (2002), seria que o sistema evolucionário não levaria a economia necessariamente ao ponto ótimo de eficiência e os indivíduos e suas preferências na visão neoclássica são dados e na visão Vebleriana são ativos no processo de evolução, tem influência e são mutáveis por meio do processo de variação, seleção e herança.

Percebeu-se uma ligação entre a evolução darwiniana na origem das espécies com três preceitos fundamentais - variação, seleção e herança. As espécies da biologia vivem em ambientes variados e cada uma tem o seu diálogo e esse ambiente propicia a variação, seleção e herança, colocando a existência como um processo de seleção adaptativa. Esse raciocínio, para a linha institucional, representa a evolução da estrutura social como um processo de seleção natural de instituições, colocando a inovação e o processo de mudança tecnológica como catalisadores dessas mudanças (HODGSON, 1993).

Por outro lado, a Nova Economia Institucionalista (NEI) coloca que as instituições são regras que tomam formas diferenciais e informais que a sociedade produz como padrão de comportamento (NORTH, 1991). Coase (1992) parece concordar com tal perspectiva quando afirma que sem as regras e regulamentos, a rápida e eficaz conclusão das negociações em uma economia capitalista não seria possível. "As instituições são as restrições criadas pelo homem que estruturam as interações políticas, econômicas e sociais" (NORT, 1991, p. 97). Neste sentido, configuram-se como as regras do jogo em uma sociedade (NORTH, 1991).

A nova economia institucional aponta que os indivíduos são seres dotados de capacidade de obtenção de informação incompleta e de racionalidade limitada e por estes fatores, enfrentam situações de incerteza nas quais incorrem custos de transação para a obtenção dessas informações. Com o objetivo de diminuir os custos de transação, são criadas as instituições (AREND; CARIO; ENDERLE, 2012). O principal foco da nova economia institucional concentra-se em identificar como as instituições emergem, operam, envolvem e moldam os diferentes arranjos que suportam as atividades de produção e troca, bem como estes arranjos agem para mudar as regras estabelecidas (LEMOS, 2013).

Conforme enuncia Conceição (2008a), existem três hipóteses de trabalho que aglutinam o pensamento da NEl: em primeiro lugar, as transações e os custos a ela associados definem diferentes modos institucionais de organização; em segundo lugar, a tecnologia, embora se constitua em aspecto fundamental da organização da firma, não é um fator determinante da mesma; e, em terceiro lugar, as falhas de mercado que são centrais para a análise da conjuntura econômica.

A NEI se distancia do velho institucionalismo quando afirma que a este último falta uma teoria concreta. Nessa perspectiva, defende a visão que ao se ater nas regras e ao custo de transação, tem-se o arcabouço institucionalista com uma teoria (CONCEIÇÃO, 2008a). No entanto, dada a riqueza teórica da temática institucionalista, Lemos (2013, pag. 51), aponta que apesar das diferenças teóricas entre as abordagens do velho institucionalismo e da NEI, "alguns aspectos comuns 
ao núcleo de conhecimentos institucionalista permitem traçar os pontos chave de análise, quer sejam: a importância das especificidades históricas; abordagem multidisciplinar; o caráter processual com ênfase ao papel da mudança; natureza evolucionária do processo econômico."

Além disso, John Commons, segmentado como "velho institucionalista", por conferir um papel instrumental às instituições e por considerar a transação como unidade básica de análise, é um autor que aproxima a velha escola da nova, visto que sua contribuição é reconhecida pelos novos institucionalistas (CAVALCANTE, 2019). Commons (1931) coloca as instituições como um acordo coletivo para resolução de conflitos e as transações sendo o acordo inicial entre partes que permitem a existência de um sistema econômico.

A linha analítica dos velhos institucionalistas recebeu novas formulações e foi resgatada, principalmente, por Hodgson, Samuels e Rutherford, caracterizando a terceira abordagem institucional - os neoinstitucionalistas. Esta vertente defende que instituições são sistemas duradouros de regras sociais estabelecidas e incorporadas que estruturam as interações sociais. Para os neoinstitucionalistas, linguagem, dinheiro, lei, sistemas de pesos e medidas, convenções de trânsito, modos à mesa, firmas (e outras organizações) são todas instituições (HODGSON, 2001). Esta linha de pensamento, com conceitos teóricos próximos aos defendidos por Thorstein Veblen, associa instituições à hábitos, costumes e padrões de comportamento esperados, atuando em diferentes contextos (CONCEIÇÃO, 2012). Ainda segundo Conceição (2012), Veblen é a referência central para os autores dessa abordagem teórica que vinculam as instituições ao contexto evolucionário. Percebe-se, inclusive, uma aproximação aos velhos institucionalistas e um afastamento aos teóricos seguidores da NEI, visto que a questão paradigmática analisada pelos neoinstitucionalistas é a forma através da qual as coisas são feitas, e não o conjunto de regras, ou a estrutura de governança que as orientam, ou que restringem 0 comportamento humano (HODGSON, 2006).

Ao criticar a natureza estática dos problemas e modelos neoclássicos, os neoinstitucionalistas ratificam a natureza dinâmica e evolucionária da economia, primeiramente preconizada por Veblen. Neste ponto se percebe forte aproximação com a corrente dos evolucionários ou neoschumpeterianos, uma vez que estes grupos concordam em desacreditar nos preceitos de "equilíbrio", pois este não considera o contexto do fenômeno em estudo e o fato dele ser "path dependence" (CONCEIÇÃO, 2002). Arend e Cario (2010) parece defender perspectiva similar quando justificam que o processo de desenvolvimento econômico é dependente de fatores institucionais e tecnológicos e estes fatores, por sua vez, são dependentes de eventos passados e, portanto, o processo é cumulativo, ou histórico.

Os neoschumpeterianos acompanham os preceitos de Schumpeter (1982) ao afirmar que a inovação, se desdobrando em mudança tecnológica, serve de força motriz para o processo de desenvolvimento da atividade econômica capitalista. Além do realce da inovação como motor da dinâmica capitalista, o segundo ponto em comum é o abandono do referencial de equilíbrio, em função das limitações do aparato estático. Assim, ambas as teorias consideram que as análises do sistema econômico capitalista não podem ser fundamentadas nas teorias da ortodoxia neoclássica, uma vez que estas negligenciam o caráter dinâmico dos processos, bem como a incerteza em relação aos benefícios futuros das atividades inovativas, caracterizadas como endógenas ao sistema. Resgatando parte da estrutura teórica e metodológica proposta por Schumpeter (1982), os neeschumpeterianos apresentam a ideia da organização como um ser vivo produzindo e recebendo estímulos do contexto, tendo 
uma carga genética responsável por estimular ou dificultar seu processo de desenvolvimento.

Nesse primeiro momento já é possível perceber similitudes entre as escolas (institucionalista e evolucionária) no momento em que ambas buscam quebrar com a estática neoclássica e resgatando conceitos da biologia para explicar a dinamicidade do mercado. Além destas evidentes aderências entre as abordagens institucionalistas e evolucionárias, estes últimos incorporam em suas análises as instituições como sendo agentes influenciadores dos movimentos de mudança de um sistema econômico, demarcado pela complexidade (PONDÉ, 2005). "Para os evolucionários, ao mesmo tempo que as instituições não se constituem em unidade central de análise - tal qual as abordagens institucionalistas -, de outro, são elementos indissociáveis do processo dinâmico de crescimento e mudança tecnológica" (CONCEIÇÃO, 2008b, p. 16). Entendida a existência de um forte vínculo com o ambiente institucional e com as instituições, a contribuição evolucionária, a partir de um enfoque microeconômico, sustenta sua tese a partir da constituição de trajetórias de inovação à formação de novos paradigmas tecnológicos (AREND, CARIO, 2010).

Os autores Arend e Cário (2010) utilizaram-se da abordagem institucionalista e neoshumpeteriana para analisar empiricamente o desenvolvimento industrial e o desequilíbrio entre as regiões sul e norte (dividida em Serra e Planalto) do Rio Grande do Sul. Os autores recorrem a fatores históricos desde o início do século passado para compreender a dinâmica de desenvolvimento industrial sul-rio-grandense. Parte-se do pressuposto a existência de path dependencies, na qual são determinados por fatores tecnológicos e matrizes institucionais. As problemáticas do desiquilíbrio econômico do Estado do Rio Grande do Sul também são exploradas como justificativa para aplicação deste estudo e como forma de estabelecer parâmetros de análise. Os autores entendem que as instituições, suas práticas e a dinâmica capitalista podem determinar trajetórias peculiares de desenvolvimento econômico.

A origem das teorias evolucionárias emerge de duas vertentes, a primeira abordagem de Cristopher Freeman a respeito da difusão das inovações como o centro dos movimentos da econômica e na segunda abordagem encontram-se Richard Nelson e Sidney Winter que, com base nos conceitos da biologia evolucionista, buscam resgatar essa questão para a realidade das firmas, incorporando a questão tecnológica como "agente" capaz de promover o processo de "evolução das espécies" (TIGRE, 2006; LEMOS, 2013).

Nessa discussão do que é necessário para a evolução das firmas e, consequentemente do mercado econômico, Nelson (1995) e Conceição (2002) parecem concordar com o papel protagonista do processo de inovação tecnológica, da busca de conhecimento vinculado à mudança tecnológica e também na evidente dificuldade e complexidade em se formalizarem modelos de crescimento com a inclusão de instituições, dada a necessidade de evolução conjunta da tecnologia e de aspectos culturais já enraizados na sociedade.

Entretanto, deve-se reconhecer que a contribuição dos modernos economistas evolucionários sobre mudança tecnológica, preocupados com o papel das instituições no desenvolvimento econômico, tem tido poucos interlocutores (NELSON; NELSON, 2002). A correlação entre as abordagens institucionalista e evolucionária (Considerando Nelson um dos seus principais defensores), mesmo que seja evidente, é, da mesma forma, escassa. Por essa razão, Nelson e Nelson (2002) considera que a contribuição de seus trabalhos é servir como uma espécie de ponte entre as duas referidas tradições intelectuais e sugerir um caminho em que ambas possam seguir conjuntamente. 
Conceição (2008b) coloca Richard Nelson como principal referência evolucionista e sustenta seu argumento a partir da contribuição neo-schumpeteriana do referido autor em parceria com Sidney Winter (NELSON; WINTER, 1982; 2005) e também no incansável trabalho constituindo uma agenda de pesquisa sobre a relação entre as instituições e o crescimento econômico. Concordando com tal perspectiva, o presente trabalho desmembra e analisa os preceitos evolucionários de Richard Nelson, no entanto, vale destacar que na abordagem evolucionária existem inúmeros outros autores relevantes para a compreensão do panorama e desenvolvimento econômico atual.

Conforme Nelson e Winter (2005) os elementos que explicam a dinâmica da mudança são de natureza tecnológica, organizacional e também institucional. Isto implica reconhecer que o procedimento do avanço tecnológico em um processo evolucionário leva à formulação de uma teoria do crescimento cujas característica foram influenciadas pela estrutura institucional que as sustenta e que as instituições também condicionam fortemente a forma como as novas tecnologias são aceitas e absorvidas pelo sistema econômico (NELSON; NELSON, 2002).

Como forma de sintetizar a linha de raciocínio desenvolvida até aqui, apresenta-se a Figura 1 que demonstra a abordagem institucionalista, evolucionária e seus principais parâmetros de contato.

Figura 1 - Panorama institucional e evolucionário

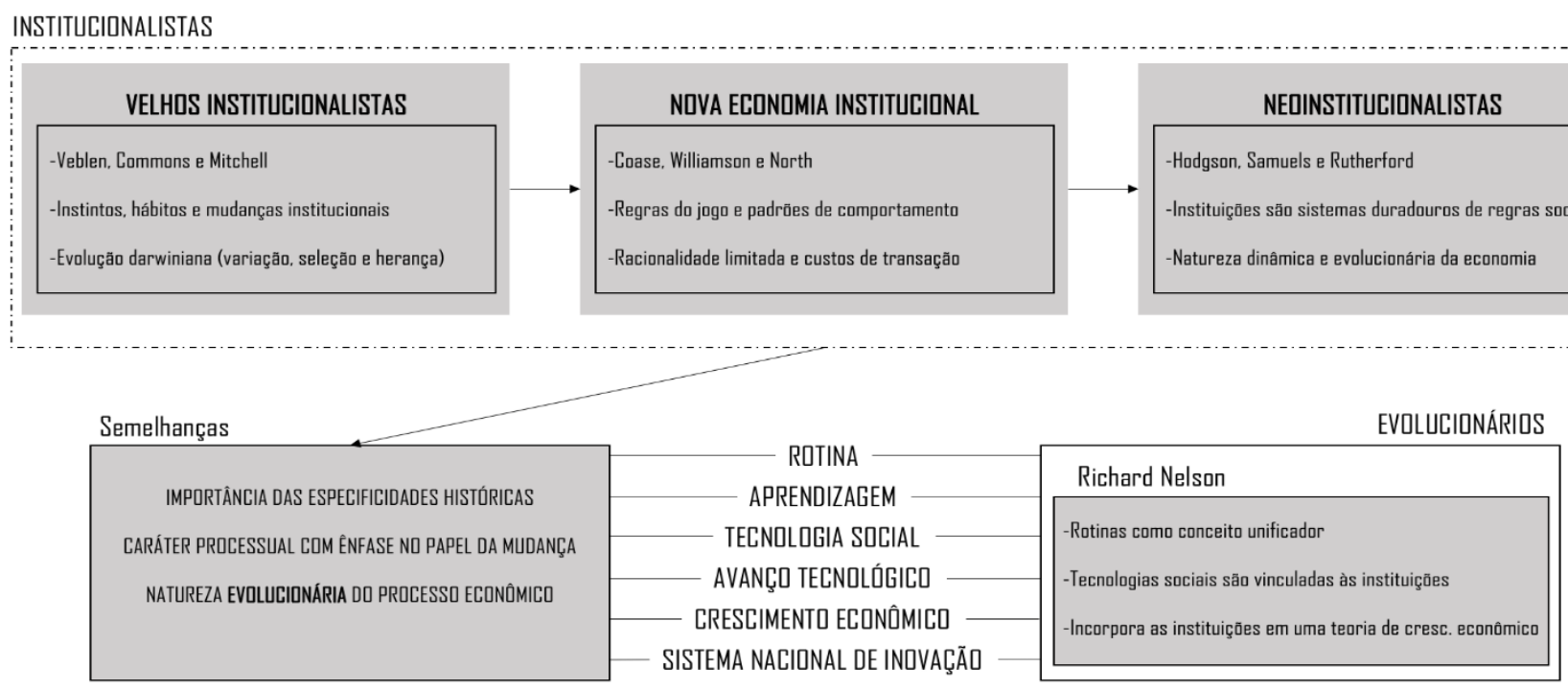

Fonte: Elaborado pelos autores.

Com base no panorama institucionalista e evolucionário delimitado anteriormente, o objetivo desse trabalho é demonstrar a aproximação entre a abordagem evolucionária de Richard Nelson com a escola institucionalista. Para alcançar o objetivo proposto, aponta-se que foram incorporados à análise trabalhos e artigos seminais dos principais autores da escola institucionalista, bem como os artigos e livros mais citados de Richard Nelson (alguns em parceria com outros autores). Além disso, outros trabalhos empíricos e teóricos de relevância para a academia foram utilizados de forma a apoiar a estrutura teórica pretendida.

Para Nelson (2006), o casamento entre as duas agendas de pesquisa é bastante viável, visto que o autor propõe a incorporação das "rotinas" enquanto conceito unificador. Depois, discute o conceito de "tecnologia social", como 
inerentemente vinculado às instituições, incorporando as instituições em uma teoria evolucionária de crescimento econômico. Por fim, o elemento final que impulsiona o desenvolvimento de uma nação deve estar baseado em um Sistema Nacional de Inovação, perspectiva abordada como quarto tópico. Esses conceitos serão discutidos na próxima sessão, seguidos da análise e das considerações finais.

\section{PRINCIPAIS CONCEITOS DE RICHARD NELSON}

\section{Rotina}

O conceito de rotina foi primeiramente proposto por Nelson e Winter (1982) e consiste na execução de tarefas de forma "programável" e por essa razão, tende a ser realizada automaticamente. Para os autores, o conceito de rotina permite a escolha dentro de um frame limitado de alternativas, uma escolha canalizada (NELSON; WINTER, 1982).

A rotina refere-se a "uma maneira de fazer algo, um curso de ação" (NELSON; NELSON, 2002). A rotina está associada em estabelecer um padrão para executar determinadas tarefas. Especificamente para Nelson, essa tarefa se refere a estabelecer um padrão tecnológico e de inovação, a rotina do aprendizado.

A falta dessa rotina do aprendizado, para Niosi (2002), está diretamente associada à problemas como a falta de eficiências institucionais. O referido autor complementa que esse padrão tecnológico deve ser incorporado nas firmas, na observação sistemática das rotinas organizacionais; essa constante busca por melhores práticas pode ser intitulada como benchmarking e deve ser utilizada tanto em organizações privadas quanto públicas (NIOSI, 2002).

Hodgson (1993) também faz considerações a respeito do papel crucial desempenhado pela rotina visto que esta auxilia os agentes a estimar as ações potenciais dos outros. Mesmo em um ambiente permeado de incertezas e complexidade, o comportamento regular é previsível e possível por meio da rotina. Ele ainda complementa que há uma evidente aproximação entre os velhos institucionalistas e os evolucionários - Nelson e Winter - quando estes últimos utilizam os "genes" como metáfora para explicar o processo de repassar habilidades e informações utilizado nas corporações modernas (HODGSON, 1993).

Uma rotina consiste em um conjunto de procedimentos que derivam em um resultado previsível e específico. As rotinas complexas tais como as que tratam da produção de bens e serviços, na maior parte das vezes, podem ser divididas analiticamente em um conjunto de sub-rotinas que fazem parte de um grande complexo de atividades que seguem um padrão de execução. Nesse sentido, Nelson e Sampat (2001) apontam que qualquer rotina particular está acoplada à incorporação de outras rotinas e esse processo pode ser infinito. Vale ressaltar que, segundo esses autores, a rotina não elimina a necessidade de decisão do gestor, apenas as canalizam para um escopo claramente definido (NELSON; SAMPAT, 2001).

Tendo em vista que a rotina pode assumir diferentes papéis no processo de inovação em uma organização, Nelson e Winter (2005) caracterizam a rotina como: (1) memória da organização, (2) trégua, (3) meta no controle organizacional, (4) fator para reprodução das rotinas existentes e (5) fator na imitação das rotinas empregadas por outras organizações.

(1) Com relação à rotina como memória da organização, os autores defendem que a sistematização de atividades pode ser uma forma de estocar determinado conhecimento. Assim, a organização "lembra fazendo" e a rotina é consolidada pela 
repetição, considerando-se que não é possível registrar em mecanismos formais todos os processos que assegurem essa memória organizacional (NELSON; WINTER, 2005).

(2) $\mathrm{Na}$ questão da rotina como trégua, parte-se do pressuposto de que nem sempre os interesses dos membros da organização são convergentes com os objetivos organizacionais e, da mesma maneira, é pouco provável que todos os integrantes estejam igualmente comprometidos com o funcionamento da organização de forma que as rotinas simplesmente sejam cumpridas. Desta forma, a operação rotineira envolve uma ampla trégua nos conflitos internos à organização, que tende a gerar uma cultura específica e compartilhada pelos agentes (NELSON; WINTER, 2005).

(3) A rotina como meta decorre em função do controle que é aplicado nos casos em que a rotina assume a qualidade de uma norma que deve ser cumprida (NELSON; WINTER, 2005).

(4) Como sendo fator para reprodução das rotinas existentes, supõe-se que é possível copiar rotinas pelo estabelecimento de uma mesma rotina numa fábrica idêntica à original. Da mesma forma, uma firma com uma rotina estabelecida pode dar escalabilidade para seus processos, utilizando seus recursos para tentar aplicar e replicar aquele mesmo formato de produção em uma escala maior (LEMOS, 2013).

(5) "Por fim, há ainda o caso em que a meta é seguir a rotina de outra firma, ou seja, utilizar a estratégia da imitação" (LEMOS, 2013, p. 53).

Para Pondé (2005), o tratamento das firmas conforme um conjunto de rotinas proposto por Nelson e Winter, dão ênfase ao pilar cognitivo das instituições. Este pilar, para Scott (2008), fundamenta seus elementos básicos nas regularidades do comportamento social incorporadas em conhecimentos e rotinas a partir de diferentes contextos. Essa base institucional alicerçada em um pilar cognitivo decorre da perspectiva evolucionária de que os modelos mentais moldam as percepções, reação aos estímulos e condutas dos indivíduos, fatores cruciais para desencadear os processos de aprendizado; ou seja, possibilita compreender como os agentes econômicos concebem o mundo, como aprendem e como usam o conhecimento adquirido (FELIPE, 2008).

Especificamente em relação ao processo de aprendizagem, as rotinas desempenham papel relevante, em função da existência da racionalidade limitada dos indivíduos. Os evolucionários resgatam o conceito de racionalidade limitada, proposto por (SIMON, 1962), o qual afirma a existência de uma capacidade limitada de processamento de todas as informações necessárias para a tomada de decisão do agente econômico. Uma das formas de ampliar as fronteiras da racionalidade limitada é estimular o processo de aprendizagem que, para Felipe (2008) são oriundos de três fontes (by doing, using ou interacting) e só podem ser caracterizados como aprendizados efetivos, à medida que, mudando a forma de percepção do indivíduo, se revertem em ações concretas, levando a práticas diferenciadas.

Nesse contexto, destaca-se o papel dos processos de aprendizagem como fatores preponderantes da difusão de inovações a partir da rotinização das atividades. Ou seja, as firmas devem investir esforços para desenvolver uma cultura de inovação baseada em processos rotineiros, que busquem avançar diante dos limites da capacidade tecnológica das organizações. Vale reforçar que os processos de aprendizagem não são restritos apenas às atividades formais de pesquisa e desenvolvimento, como também se referem às formas e mecanismos que contribuem para a interação entre empresas e outros agentes (CASSIOLATO; CAMPOS; STALLIVIERI, 2007). 
Nelson e Sampat (2001) afirmam que as rotinas são um "veículo útil" que caracterizam as tecnologias sociais. "De fato, uma razão importante para se confiar em tecnologias sociais padronizadas é que os agentes podem usar o conhecimento público acumulado útil para realizar essas rotinas" (NELSON; SAMPAT, 2001, p. 22). Ainda para esses autores, uma das características que permite a associação da rotina com o conceito de tecnologia social é em função do quanto ela (rotina) envolve a habilidade humana em criar e nomear um caminho para aquilo que deve ser feito de uma forma clara, provendo razões e explicações para tal.

Um programa incorporado em uma rotina geralmente envolve dois aspectos diferentes: uma receita sem características específicas em relação à divisão do trabalho e uma divisão do trabalho com um modo de coordenação (NELSON; SAMPAT, 2001). Os estudiosos geralmente têm o primeiro aspecto em mente quando concebem "tecnologia" no sentido convencional; esse aspecto da rotina de tecnologia "física" envolvida. E o segundo aspecto envolve a coordenação das ações humanas que é intitulado de tecnologia social envolvida.

As tecnologias sociais padronizadas podem operar no sentido de "restringir rotinas dentro das organizações, quando existem noções amplamente aceitas de como um determinado negócio deve funcionar num certo contexto, assumindo assim o caráter de normas estabelecidas. Assim as instituições definem ou induzem tecnologias sociais particulares que são pensadas como formas apropriadas de organizar a atividade econômica. Desta forma, as tecnologias sociais empregadas diferem na extensão em que são suportadas por valores e normas" (LEMOS, 2013, p. 93).

\section{Tecnologia Social}

Richard Nelson afirma que existem inúmeras concepções do que são instituições - as regras básicas do jogo (D. North), estruturas de governança (O. Williamson), ou costumes e padrões usuais de comportamento em contextos específicos (T. Veblen e G. Hodgson) e que isso constitui um conjunto muito heterogêneo de coisas que dificultam um entendimento adequado do que seja 0 "bestiário "instituições" (NELSON, 2006, p. 5-6). Devido a isso, contrapondo-se à postura de orientação macroeconômica de que basta ter as "instituições certas" ou estabelecer as "regras do jogo", Richardo Nelson assume a posição de que uma concepção mais útil sobre o que são instituições abarcaria uma grande variedade de coisas diferentes, em contextos analíticos distintos, mas com foco definido pelo que as instituições fazem (SUZIGAN; FURTADO, 2010).

A partir disso, Nelson e Sampat (2001) propõem o conceito de tecnologia social, que se diferencia do conceito de tecnologia física da mesma forma em que, segundo o autor, "numa receita de bolo, a receita seria a tecnologia física, e a maneira como o trabalho é organizado e coordenado para fazer o bolo seria a tecnologia social". O termo "tecnologia" refere-se à comportamentos cujo propósito é de realizar determinadas tarefas, e o termo "social" significa que esses comportamentos envolvem (ou respondem a ações de) múltiplos agentes (NELSON, 2006, p. 11-13).

O conceito de tecnologia social engloba comportamentos associados às coisas que são realizadas dentro de uma organização bem como aquelas que envolvem diferentes indivíduos ou organizações. De uma forma geral, o conceito também pretende incluir os aspectos relacionados aos objetivos que orientam a forma de fazer 
as coisas onde o comportamento dos agentes é adaptado para influenciar as ações ou reações dos outros agentes (NELSON, 2006; LEMOS, 2013).

Resgatando os três conceitos de instituições, as tecnologias sociais que prevalecem em cada contexto são sustentadas por condicionantes mais gerais, dados pelas chamadas regras do jogo, pelas estruturas e mecanismos de governo, modos usuais de efetuar transações e interações, e instituições não-mercado, inclusive políticas e instituições específicas a indústrias ou tecnologias (NELSON; SAMPAT, 2001). Para o autor, a concepção de instituições abarca as diferentes definições desse termo, principalmente aquelas mais amplamente utilizadas na literatura. Como indica essa discussão, o conceito de tecnologia social é amplo o suficiente para abranger ambos os modos de organizar as atividades de um contexto organizacional (NELSON; NELSON, 2002).

Nelson (2006, p.16) ressalta que "cada tecnologia social envolve estruturas de governo específicas e leis particulares. Algumas oferecem o contexto no qual tecnologias sociais específicas evoluem. Outras mudam como parte essencial do processo evolucionário". Ressalta ainda que, em muitos casos, novas instituições significam novas maneiras de fazer coisas. Com base nisso, a produtividade e efetividade das atividades econômicas dependem tanto das tecnologias físicas como sociais, que são determinadas por fatores como leis, normas, expectativas, estruturas de governança, costumes e outros mecanismos que as sustentam e, principalmente, as padronizam (CONCEIÇÃO, 2009).

Para Conceição (2012), Nelson propõe que as tecnologias sociais possam ser "auto institucionalizadas" de inúmeras maneiras. Em primeiro lugar, comportamentos de costumes, modos de interação e de organização se autor reforçam (self reinforcing) porque são esperados, são familiares (resgata-se aqui, o conceito da rotinização das tarefas), em que qualquer ação diferente desse padrão provocaria uma reação inibidora. Como segundo ponto, as tecnologias sociais são autossustentáveis, ou seja, tendem a existir dentro de sistemas que vinculam umas às outras. Em terceiro lugar, as tecnologias sociais (assim como as tecnologias físicas), tem a tendência de evoluir com o tempo, em função da experiência e conhecimento acumulado ao longo do processo (CONCEIÇÃO, 2012). Tal quadro estabelece um padrão de sinergias e de estabilidade que permite à sociedade avançar, ora criando novas tecnologias sociais, ora substituindo as velhas. Isto reforça o argumento segundo o qual esta agenda de pesquisa deve aprofundar-se no papel das instituições e da mudança tecnológica e institucional sobre os rumos do processo de crescimento econômico.

Nelson (2006) propõe que o reconhecimento explícito do conceito de tecnologia social, juntamente com a compreensão de que uma variedade de fatores diferentes influência as tecnologias sociais habitualmente utilizadas em um contexto particular, ajudam a esclarecer por que o termo "instituição" tem sido usado para cobrir tantas coisas aparentemente díspares. Conforme apontado pelo autor, quase sempre haverá um número de diferentes "instituições" que apoiam e restringem determinadas tecnologias sociais, e elas operam de maneiras diferentes (NELSON, 2006). Algumas instituições têm um efeito amplo e um pouco difuso sobre as tecnologias sociais usadas ou não.

O "porém" dessa discussão ocorre quando Nelson (2010) argumenta que em função dos avanços e facilidades tecnológicas, as tecnologias físicas podem ser muito mais fáceis de aprender e adquirir do que as tecnologias sociais. Essa evolução desigual pode acarretar inúmeros problemas visto que a operação efetiva de muitas tecnologias físicas requer a implementação de várias tecnologias sociais. Com base nisso, "pode ser muito mais fácil importar o maquinário e adquirir o conhecimento de 
engenharia para produzir automóveis modernos ou semicondutores do que estabelecer uma organização firme e uma estrutura de gerenciamento eficaz para operar a tecnologia física ou estabelecer um conjunto efetivo de procedimentos para a aquisição, insumos, ou para marketing" (NELSON, 2004, p. 366).

$\mathrm{Na}$ medida em que as tecnologias sociais se tornam institucionalizadas, estabelecem bases sólidas para que as tecnologias físicas evoluam e esta coevolução é fundamental para a consolidação dos sistemas de inovação (PEREIRA; DATHEIN, 2012). Nelson (2008) aponta que essa coevolução das tecnologias físicas e sociais é o fator que permite entender como a inovação impulsiona o crescimento econômico.

Para Conceição (2012) este processo de evoluir em conjunto coloca as instituições como elementos decisivos para o crescimento econômico, uma vez que estas podem tanto gerar as condições que permitam os avanços tecnológicos como atrapalhar tais avanços, caso não existam coordenação e estratégias adequadas em relação à orientação do paradigma tecnológico. No entanto, conforme já assinalado anteriormente, as tecnologias sociais são mais difíceis de serem controladas, pois estão atreladas às condutas humanas, de maneira que sua evolução se configura como um processo incerto, quando comparado às tecnologias físicas (NELSON, 2008).

A partir disso, conectar instituições e crescimento implica estabelecer uma coerente análise das relações entre instituições, mudança institucional e avanço tecnológico e, acrescentar a "tecnologia social", que serve como suporte analítico e diferenciado à noção, já estabelecida, de "tecnologias físicas". Como o crescimento econômico envolve a coevolução de tecnologias físicas e sociais, então as instituições são decisivas para seu efetivo avanço (NELSON, 2008).

Sabendo disso, mirando rumo ao crescimento econômico, algumas instituições podem gerar condições sobre as quais os avanços tecnológicos possam ocorrer e outras sustentam o desenvolvimento de novas tecnologias fundamentais. Porém, como o processo de crescimento e de avanço tecnológico é permeado por desconfiança e incerteza, e partindo do pressuposto da existência de racionalidade limitada dos agentes, as instituições podem até mesmo atrapalhar o respectivo avanço, se não houver coordenação e estratégias adequadas em relação à orientação do paradigma tecnológico (CONCEIÇÃO, 2012).

\section{Crescimento Econômico}

Conceição (2008a) traz algumas contribuições de Nelson (2002) sobre a importância das instituições para o crescimento econômico, partindo da crítica da economia neoclássica para responder adequadamente o papel da tecnologia neste processo. A teoria neoclássica é incapaz de caracterizar o processo de crescimento econômico desencadeado pela mudança tecnológica (NELSON; WINTER, 1982). Em particular, o modelo neoclássico desconsidera o fato de que os esforços para o avanço tecnológico são, em grande medida, "cegos". Tal proposição não implica negar o propósito, a inteligência e o corpo de entendimento das tentativas em se avançar na forma de incorporar o avanço tecnológico.

A partir daí se constata que a própria noção de instituição, em função das raízes históricas e estruturais que Ihe são específicas, passa a viabilizar distintas trajetórias de crescimento, em seus respectivos ambientes socioeconômicos. Por esta razão instituição e crescimento econômico são conceitos umbilicalmente vinculados (CONCEIÇÃO, 2008b). 
Em artigo que trata acerca do papel das instituições como fator que regula o desempenho econômico, Nelson e Sampat (2001) esclarecem que em um primeiro momento, uma teoria do crescimento econômico é uma teoria dinâmica da produção, especificamente, é um arcabouço teórico de fatores que impulsionam a troca do produto pelo trabalhador. Caracterizando o processo de "crescimento econômico", Nelson (2006) afirma que este deve ser entendido como um processo evolucionário guiado pela inovação. Nesse sentido, dentre os inúmeros fatores que proporcionam o crescimento econômico de uma nação, estudiosos desse campo parecem ter chegado em comum acordo de que os fatores causais imediatos ou próximos de grandes incrementos cumulativos na produtividade envolvem elementos chave como o avanço tecnológico, a transformação de capital físico e o desenvolvimento do capital humano (NELSON; SAMPAT, 2001; NELSON, 2006).

O que é responsável por fazer uma economia ser caracterizada como produtiva e progressiva? A costume atual, tanto entre economistas quanto no argumento público, é ver "as instituições certas" como a resposta à essa questão. Esse foco contemporâneo nas instituições surge como resultado de uma longa jornada intelectual por meio da qual economistas modernos, interessados em entender as fontes de diferenças de produtividade entre as nações e os processos de crescimento econômico, gradualmente ampliaram e aprofundaram sua análise (NELSON, 2006; 2008).

Em se tratando de crescimento econômico de diferentes nações, de acordo com uma perspectiva institucionalista, a história importa, as formas de crescimento capitalista são diferenciadas e múltiplas, o processo de crescimento é contínuo e tem raízes históricas profundas (NORTH, 2005; HODGSON, 2006). Na perspectiva evolucionária, o crescimento econômico precisa ser compreendido como resultado da progressiva introdução de novas tecnologias, associadas a níveis crescentemente mais elevados da produtividade do trabalho, à habilidade em se produzir novos e melhores bens e serviços.

Conceição (2002) ao revisitar a agenda evolucionária, aponta que para os teóricos dessa vertente, o desenvolvimento econômico contém pelo menos três componentes: path dependence, retornos crescentes dinâmicos e a interação entre ambos. A ideia presente em todos os modelos dessa natureza é que as firmas, no longo prazo, sobrevivem influenciadas por eventos, que, em grande parte, são "randômicos", tal que se especializam em tipos particulares de tecnologia, que também são resultantes de eventos randômicos preliminares. Ou seja, o nível de opções tecnológicas desenvolvidas pelas firmas é também fruto de opções relativamente aleatórias, decididas em períodos anteriores (CONCEIÇÃO, 2000). Então, os "retornos crescentes dinâmicos" tornam o path dependence particularmente forte.

Nesse sentido, conforme apontado por Pereira e Dathein (2012), algumas condições devem ser consideradas para a compreensão do processo de desenvolvimento econômico a partir da abordagem "institucionalista- evolucionária": (1) deve-se levar em conta o fato de que as economias capitalistas são dinstintas em relação às suas trajetórias de crescimento a partir dos arranjos institucionais e da sua estrutura produtiva vigente; (2) os processos de mudança têm raízes históricas (embedded); (3) o comportamento das empresas é determinante para a ocorrência de mudanças tecnológicas, na medida em que são consideradas instituições de produção, de negócios e de aprendizado.

A questão de como as instituições se ajustam a uma teoria de crescimento econômico depende não somente da forma como a definimos, mas de outros aspectos 
teóricos tais como compreender o formato de concepção de instituição, enquanto "tecnologias sociais", se adapta às teorias evolucionárias de crescimento econômico (CONCEIÇÃO, 2008b).

Nessa formulação, as novas "instituições" e tecnologias sociais aparecem como mudanças nos modos de interação - novos modos de organização do trabalho, novos tipos de mercados, novas leis, novas formas de ação coletiva -, que são chamadas, como as novas tecnologias, a trazer novos usos econômicos:

" [...] In turn, the institutional structure at any time has a profound effect on, and reflects, the technologies that are in use, and which are being developed $[\ldots]$ " (NELSON; NELSON, 2002, p. 23).

Portanto, para Conceição (2008a, p. 19) o conceito de instituições enquanto "tecnologias sociais", a linguagem das rotinas para descrevê-las e a teoria sobre como as instituições e a mudança institucional emergem com o avanço das tecnologias físicas no processo de crescimento econômico, vêm se tornando "noções bastante poderosas, aproximando a análise da forma de ação das referidas tecnologias sociais".

Resgatando um conceito schumpeteriano, Nelson (2006) afirma que o processo de crescimento econômico implica, muitas vezes, em uma "destruição criadora" de velhas maneiras de fazer as coisas e de agentes econômicos que tem dificuldade a se adaptarem a novas e mais eficazes formas de realizar determinadas tarefas. Nesse sentido, o processo de aprendizado, mais uma vez tem papel preponderante e passa a ser entendido como o "elo de ligação" entre inovações (estruturais e institucionais) e desenvolvimento econômico, representando um acúmulo de competências e capacitações, no qual o fator humano e a organização produtiva são agentes centrais da mudança. Ou seja, o conhecimento gerado a partir do processo de aprendizado é a essência do desenvolvimento econômico (LUNDVALL et al., 2002).

Dito isso, do ponto de vista da teoria evolucionária, o crescimento econômico deve ser entendido como o resultado da introdução progressiva de novas tecnologias, associadas a níveis cada vez mais altos de produtividade do trabalhador e à capacidade de produzir bens e serviços novos ou aprimorados (NELSON; NELSON, 2002). Em outras palavras, Nelson ressalta a importância de diversos atores e agentes no processo, e da necessidade de integração destes para a promoção do crescimento econômico, apresentando então o conceito de Sistemas Nacionais de Inovação.

Kretzer (2009) aponta que na medida em que o conceito tende a se difundir nos meios acadêmicos e de formuladores de políticas, o tema crescimento e desenvolvimento econômico assume um caráter crítico diante de um contexto caracterizado pela chamada globalização. Para o autor, o foco sobre sistemas nacionais assume importância, na medida em que as instituições, ao se sentirem ameaçadas, iniciam um entendimento ou um reconhecimento de sua importância e de suas funções fundamentais em relação a certas atividades de inovação (KRETZER, 2009).

\section{Sistema Nacional de Inovação}

"A proposta básica é que diferentes eras econômicas são impulsionadas pelo desenvolvimento de grupos específicos de tecnologias e que as restrições institucionais necessárias para explorar e apoiar esses grupos podem variar significativamente. A ideia dos sistemas de inovação é claramente aparente aqui" (NELSON; NELSON, 2002, p. 7). 
Segundo Fagerberg e Verspagen (2007), uma empresa não inova sozinha e, portanto, depende de uma forte interação com o ambiente para poder promover as mudanças técnicas necessárias, percorrer a trajetória tecnológica, estimular o processo de aprendizado organizacional e solucionar um problema constituído a partir da base de um paradigma tecnológico. É percebido então, a necessidade de um processo sistêmico capaz de conduzir e estimular os processos inovativos das diversas instituições que constituem uma economia capitalista. $\mathrm{O}$ esforço em conjunto de empresas, universidades, agências de fomento ao desenvolvimento, Estado, laboratórios governamentais e institutos de pesquisa é requerido para avançar o caminho da trajetória tecnológica. Tal movimento pode ser referenciado pela abordagem do Sistema Nacional de Inovação (SNI) (LEMOS, 2013).

A perspectiva do SNI surgiu a partir do trabalho de Friederich List (1909), no entanto, a nomenclatura foi primeiramente utilizada por Cristopher Freeman (1988). Para Nelson e Nelson (2002), o termo inovação é em referência aos processos e produtos inovativos colocados no mercado pelas empresas; o termo sistema é em função do conjunto de atores necessários para manter o desempenho inovador; e o termo nacional refere-se ao ambiente de um país que facilita ou dificulta a implementação das inovações (LEMOS, 2013).

Nelson (2013) aponta que o conceito de 'sistema de inovação', quer seja ele definido globalmente ou ao nível da nação, setor industrial, tecnologia ou região, tem sido uma das temáticas discutidas tanto entre pesquisadores quanto políticos, dada sua relevância para o desenvolvimento de uma nação. "O conceito de um sistema nacional de inovação foi proposto virtualmente simultaneamente por Bengt-Ake Lundvall, Christopher Freeman e eu. Este certamente não foi um caso de descoberta independente. Todos nós três fazíamos parte de um grupo de estudiosos relativamente próximos que estudavam o avanço técnico. Nossas primeiras discussões do conceito foram todas publicadas em Dosi et al., (1988). Nós conversamos muito um com o outro. A ideia claramente era "no ar". E o nome para essa ideia era o óbvio" (NELSON, 2013, p. 16)

Fernandes e Lima (2018), destacam que houve um crescimento expressivo na literatura sobre sistema nacional de inovação (SNI) que vem ocorrendo desde a década de 90, reflexo da sua influência sobre investigações acerca do desempenho econômico de países e regiões. Por trás do conceito de SNI, há um complexo contexto institucional que caracteriza e envolve uma diversidade de atores, tais como firmas, universidades, institutos de pesquisa, governos, agências financeiras e arcabouço regulatório, bem como uma divisão de trabalho e canais de comunicação que ligam os atores entre si (FERNANDES et al., 2010).

Segundo Nelson (2004), a diversidade dos arranjos que configura os sistemas de inovação é grande e pode ser percebida a partir de características como: as especificidades das firmas inovadoras de cada país, a relação dessas firmas com as instituições de pesquisa, o peso dedicado à ciência básica, o papel do governo na articulação das instituições do sistema e os diferentes arranjos do sistema financeiro para impulsionar e formar agentes e profissionais para alimentar o processo (NELSON, 2004)

O SNI pode ser conceituado como um conjunto de instituições que influenciam o desenvolvimento, difusão e uso de inovações (EDQUIST, 2006). Sua atividade central é o aprendizado que se refere a uma atividade social de interação entre indivíduos. O SNI tem como características ser um sistema aberto e heterogêneo, podendo ser local e nacional ao mesmo tempo. Ressalta-se que os atores que compõe 
- SNI e suas relações, dependem das características culturais, econômicas e institucionais de cada país (LUNDVALL, 2007).

Acerca disso, Edquist (2006) e Nelson (2008) enfatizam o papel das instituições e dos atores que criam, desenvolvem e difundem as inovações, bem como os canais de interação que conectam os envolvidos. Para esses autores, a compreensão sobre o processo inovativo deve considerar que, a partir do seu caráter sistêmico, o processo não é linear, é interativo e determinado socialmente (EDQUIST, 2006; NELSON, 2008).

Nesse sentido, deve-se considerar que as empresas são organizações incorporadas no ambiente político e socioeconômico do país que refletem a sua trajetória cultural e histórica (path dependence). Assim, o sistema de inovação é um conjunto de instituições que contribuem para o desenvolvimento da inovação e da capacidade de aprendizado de um país, região e setor (PARANHOS; PERIN, 2018). As principais características envolvem a ênfase nas trajetórias históricas e a compreensão de diversos elementos e relações referentes à produção, assimilação e difusão do conhecimento (FAULKNER; SENKER, 1994). Para Lundvall (2007), devido ao caráter sistêmico e abrangente de um SNI, é importante considerar em sua análise a existência de muitas dimensões como a produtiva, social, institucional, política e financeira e a interação entre elas.

Acerca disso, Kretzer (2009) afirma que os sistemas de inovação podem ser delimitados a partir de uma dimensão geográfica. Lundvall (2007), em perspectiva similar, afirma que é necessário a análise dos sistemas de inovação por uma perspectiva menos ampliada e mais objetiva e focada. O Sistema Regional de Inovação baseia-se em um raciocínio semelhante à SNI, sob uma perspectiva regional (LEMOS, 2013). Resgatando a necessidade de aprendizado para gerar inovação e do papel do conhecimento tácito nesse processo, ressalta-se que este último é facilitado pela proximidade geográfica o que colabora para a disseminação da abordagem do SRI.

"Tanto na perspectiva dos SNIs quanto nos SRIs, identifica-se que as universidades são referenciadas em diferentes momentos como atores constituintes dos sistemas de inovação, onde desempenham importante papel nas interações que firmam com as empresas, seja fornecendo infraestrutura ou recursos humanos para inovação, seja dinamizando processos de aprendizado ou promovendo transferência de conhecimento" (LEMOS, 2013, p. 69).

Para Mazzoleni e Nelson (2005), o conceito do Sistema de Inovação concentrase na gama de instituições envolvidas no processo de inovação e, de fato, na maioria das indústrias, os papéis das empresas são centrais. No entanto, segundo os autores, há uma perceptível tendência de muitos economistas e teóricos discutirem sobre inovação como se apenas as empresas fossem "a história completa", negligenciando outros tipos de instituições que estão envolvidas nos processos que apoiam e moldam a inovação em muitas indústrias modernas (maioria). Deve-se argumentar que as instituições de pesquisa pública desempenham um papel importante no século XXI e devem ser agentes integrados e analisados no "modelo" dos SNIs (MAZZOLENI; NELSON, 2005).

\section{APROXIMAÇÃO ENTRE NELSON E OS INSTITUCIONALISTAS}

Com base no exposto até aqui, entende-se que há, de fato, uma confluência entre as abordagens institucionalistas, em destaque maior o Velho institucionalismo e 
o Neoinstitucionalismo com a abordagem evolucionária, mais especificamente, a linha teórica seguida por Richard Nelson. Isso pode ser observado no trabalho de Nelson e Sampat (2001) que, apesar da aparente diversidade na literatura sobre como as instituições são definidas, existe uma relação familiar pelo menos em relação às intenções dos escritos em aproximar estes dois elementos analíticos. De forma explícita ou implícita, os autores sugerem que o conceito de "tecnologia social" é útil para a reflexão acerca das instituições, visto que envolve uma ampliação do modo como os economistas conceituam uma "atividade" econômica.

Nesse sentido, Sampat e Nelson (2001) defendem uma visão mais ampla do termo "instituições", o qual é usado, geralmente, pela maioria dos economistas para denotar estruturas e forças que moldam e mantêm tecnologias sociais predominantes.

"A proposta de abordagem analítica para instituições é focar nas tecnologias
sociais predominantes de interesse e ser elética, inclusiva sobre as
"instituições" que as apoiam. Sob essa orientação, as instituições certamente
se revelam uma diversidade de coisas. Mas isso me parece ótimo, na verdade
esclarecedor, se o objetivo da pesquisa é explicar por que as tecnologias
sociais predominantes são o que são e como mudam" (NELSON, 2008, p. 3).

Em outro texto, Nelson e Nelson (2002) também enfatizam a entrelaçada relação entre tecnologias sociais e as instituições. Os autores propõem que a concepção de instituições como tecnologias sociais se enquadra muito bem com as definições de instituições mais amplamente utilizadas na literatura. Isso se encaixa na noção de instituições de Veblen como "hábitos gerais de ação e pensamento". As instituições sociais certamente são definidas e definem "as regras do jogo", o conceito de instituições empregadas por muitos estudiosos, incluindo Douglass North. As tecnologias sociais também podem ser vistas como "modos de governança" amplamente empregados, que é a noção de Williamson sobre o que são as instituições. E na linguagem dos custos de transação, que é amplamente utilizada na literatura institucional, as "tecnologias sociais" geralmente implicam em formas de realizar determinada tarefa, objetivando reduzir os custos de transação. Como essa discussão indica, o conceito de tecnologia social é amplo o bastante para abranger tanto os padrões de pensamento existentes que conduzem o formato de realizar as tarefas quanto as formas de organizar e gerenciar a atividade dentro de determinadas organizações.

Conceição (2008) parece concordar com tal perspectiva afirmando que a amplitude e a complexidade do pensamento institucionalista, não podendo ser patrimônio de uma única e exclusiva "visão", conferem à teia de múltiplas concepções a possibilidade de se avançar em direção a uma "teoria da dinâmica das instituições". Com base nisso, demonstrou-se que os autores analisados e suas respectivas correntes vêm cumprindo com êxito essa agenda de pesquisa, permitindo a visualização de uma "teoria dinâmica das instituições".

Dada a natureza ativa e multifacetada das abordagens institucionalistas, fica evidente que tal tarefa não pode se realizar sob a tutela de uma única e exclusiva abordagem, que se auto-reivindique institucionalista, mas que a referida "construção" se realize com a confluência das várias contribuições (CONCEIÇÃO, 2008). O mesmo autor aponta que a crítica ao equilíbrio de longo prazo como meta final do processo de crescimento econômico, traduziu-se no grande legado do "antigo institucionalismo", cuja contribuição de Richard Nelson, um dos interlocutores evolucionários, mesmo sem a pretensão de se intitular "instuticionalistas", tratou de dar substância e consistência teórica. O pensamento institucionalista moderno é impensável sem a 
incorporação da referida abordagem evolucionária de Nelson, mais especificamente sem o conceito de rotina, tecnologia social, a necessidade de aprendizagem para 0 crescimento econômico e a necessidade de fomento de um sistema nacional de inovação.

A questão da importância das instituições demonstra no marco teórico a forma em que as modernas vertentes do institucionalismo trataram as questões relativas à dimensão do processo de crescimento econômico. Tal perspectiva sugere uma nítida confluência com a visão de Richard Nelson. As modernas vertentes institucionalistas (NEI e Neo-institucionalistas) vêm revelando uma clara convergência teórica com a agenda de pesquisa evolucionária sobre crescimento econômico, conforme proposição feita por Richard Nelson (2008). Isto também se sintoniza com os princípios evolucionários implícitos ao pensamento de Veblen, os quais constituem a principal referência da corrente denominada de Neoinstitucionalismo. Estas confluências entre a escola institucionalista e a linha de pensamento evolucionária de Nelson é sintetizada no Quadro 1.

Felipe (2008) também parece perceber aproximação entre os institucionalistas e os evolucionários na voz de Nelson, quando afirma que embora não constitua uma escola institucionalista, scricto sensu, os neoschumpeterianos incorporam a análise das instituições, em um arcabouço evolucionista, como influenciando os movimentos de mudança estrutural de um sistema econômico, marcado pela presença de complexidade e criatividade.

Nesse sentido, agrupar de forma mais sistemática as instituições à metodologia evolucionária de Nelson, passa a ser condição necessária para avanços explicativos da realidade. Assim, mesmo que para os evolucionários as instituições não sejam objetos centrais de análise - como fazem as escolas institucionalistas -, "constituemse em elementos indissociáveis do processo dinâmico de crescimento, desenvolvimento e de mudança tecnológica" (NELSON, 2008, pg. 2).

Com base no exposto até aqui e segundo Arend, Cario e Enderle (2012), processos de busca, rotinas, seleção e aprendizado que cercam a atividade inovativa ocorrem num ambiente dinâmico, incerto e diversificado, podendo conferir distintas trajetórias. Os neo-schumpeterianos, mesmo centrados na mudança técnica, consideram importante o papel das instituições, pois elas podem definir padrões ou trajetórias de desenvolvimento econômico distintos. 


\section{Quadro 1- Confluência entre abordagens}

\section{INSTITUCIONALISTAS}

A rotina auxilia os agentes a estimar as ações potenciais dos outros (HODGSON, 1993)

\begin{abstract}
Veblen combate a ideia de imutabilidade dos indivíduos diante das pressões do ambiente, considerando sua natureza evolucionária e 0 processo de aprendizagem como elementos influenciadores do comportamento (MONASTÉRIO, 1998).

O conhecimento não depende apenas da capacidade intelectual do indivíduo, mas também é fruto de sua interação com outros indivíduos em um determinado ambiente, caracterizando um processo de aprendizagem coletivo (HODGSON, 1999). Veblen (1898) e Mitchell (1910b), entendiam as instituições como hábitos mentais, no sentido de pensamentos predominantes que ganharam aceitação geral como normas de conduta.
\end{abstract}

a Nova Economia Institucionalista (NEI) coloca que as instituições são regras que tomam formas diferenciais e informais que a sociedade produz como padrão de comportamento (NORTH, 1991).

As que instituições são sistemas duradouros de regras sociais estabelecidas e incorporadas que estruturam as interações sociais (HODGSON, 2001).

A própria noção de instituição, em função das raízes históricas e estruturais que lhe são específicas, passa a viabilizar distintas trajetórias de crescimento, em seus respectivos ambientes socioeconômicos. Por esta razão instituição e crescimento econômico são conceitos umbilicalmente vinculados (CONCEIÇÃO, 2008b).

A natureza dinâmica e evolucionária das instituições, defendida pelos velhos e neoinstitucionalistas, concede à inovação o papel de agente catalisador, estabelecendo os mecanismos necessário para o surgimento de um sistema coeso de apoio mútuo rumo ao desenvolvimento (HODGSON, 1993; CONCEIÇÃO, 2002).

\section{ELEMENTO ANALÍTICO}

Rotinas
Os processos

de aprendizagem são fatores preponderantes da difusão de inovações a partir da rotinização das atividades (NELSON; SAMPAT, 2001) . Tecnologia
social

Crescimento econômico
As tecnologias sociais que prevalecem em cada contexto são sustentadas por condicionantes mais gerais, dados pelos hábitos mentais, regras do jogo, pelas estruturas e mecanismos de governo, modos usuais de efetuar transações e interações, e instituições nãomercado, inclusive políticas e instituições específicas a indústrias ou tecnologias (NELSON; SAMPAT, 2001).

Caracterizando 0 processo de "crescimento econômico", Nelson (2006) afirma que este deve ser entendido como um processo evolucionário guiado pela inovação.

Para Mazzoleni e Nelson (2005), o conceito do Sistema de Inovação concentra-se na gama de instituições envolvidas no processo de inovação, colocando as empresas como agentes centrais.

Fonte: Os autores 


\section{CONSIDERAÇÕES FINAIS}

O objetivo do artigo foi demonstrar a aproximação entre a abordagem evolucionária de Richard Nelson com a escola institucionalista. Desse modo, mesmo que os institucionalistas enfoquem, predominantemente, as instituições; e os teóricos evolucionários, especificamente Richard Nelson, utilizem, como principal elemento analítico, as "tecnologias", é possível perceber que os autores aqui analisados e suas respectivas correntes vêm demonstrando diversos pontos de contato e similaridade em suas teses. Vale ressaltar que tal esforço não pode se realizar sob a tutela de uma única e exclusiva abordagem institucionalista, mas que a referida "construção" se realiza com a confluência das várias contribuições, como as discutidas neste estudo.

A partir do exposto na análise, é possível defender a existência de uma teoria dinâmica das instituições, a qual integra tanto aspectos micro, quanto macroeconômicos, vinculando, de maneira mais estrita, o processo de crescimento ao ambiente tecnológico, às mudanças estruturais, à inovatividade e, naturalmente, ao desenho institucional que o sustenta.

Os elementos analíticos aglutinadores entre as abordagens teóricas institucionalistas e evolucionárias de Nelson apresentam, nas rotinas, o papel de perpetuação de um padrão tecnológico colocado pelo processo de aprendizagem, estabelecendo uma "rotina do aprendizado" nas instituições existentes. Essas rotinas, por sua vez, sejam hábitos mentais, regras do jogo ou regras sociais, sustentam as tecnologias sociais que prevalecem em cada contexto, ou seja, a forma de realizar determinada envolvendo múltiplos agentes.

A coevolução de tecnologias sociais e tecnologias físicas nas instituições são responsáveis por estabelecer avanço tecnológico, cuja direção é o crescimento econômico. Para que fatores contextuais, tais como racionalidade limitada, receio de comportamento oportunista e lock-in, não constituam barreiras nesse avanço, é necessário que se estabeleça uma relação de troca e sustentação entre as instituições, culminando em um sistema de inovação, seja ele nacional, regional ou local. Disso depreende-se que o crescimento e o desenvolvimento derivam não somente de investimentos e inovações, mas também de um ambiente institucional historicamente construído.

Considerando que os processos inovativos não são atos estritamente individuais e sim decorrentes do ambiente sistêmico, uma agenda de pesquisa que trate de sistema de inovação deve considerar as ações de fomento que possibilite a interação e cooperação dos atores - governo, firma, universidade, institutos de pesquisa e associações de classe. Assim como, deve considerar o conhecimento técnico dos processos inovativos - paradigma e trajetória tecnológica - existentes e os a serem impulsionados. Da mesma forma, deve demonstrar como as coisas (tecnologias sociais) são construídas e organizadas a partir de regras sociais estabelecidas e incorporadas de forma evolutiva e acumulativa. Assim sendo, demonstram como os modos de interação e cooperação se autoreforçam (self reforcing), autosustentam (uns aos outros) -, e evoluem no tempo (conhecimento e experiência) em prol do desenvolvimento.

Outros estudos envolvendo os arcabouços neoshumpeterianos /evolucionários e institucionalistas podem ser realizados na explicação do desenvolvimento inovativo. Nessa agenda figuram, por exemplo, temas como interação universidade e empresa, padrão tecnológico setorial, política industrial e tecnológica, entre outros. Alguns estudos acadêmicos foram realizados e avaliados favoravelmente como os de 
Azevedo (2016); Lemos (2013), Borges (2016) e Neuberger (2019), abrindo assim possibilidades de outras investigações acadêmicas.

De toda forma, tal marco teórico integrativo auxilia na compreensão do desenvolvimento favorável ocorrer em determinado local e período, bem como explicar as razões do insucesso em outras circunstâncias e momentos. Nesta linha, os estudos que tomam o Brasil em suas várias dimensões econômicas como objeto de análise, possibilitam compreender, empiricamente, os princípios que incentivam e impulsionam, bem como engessam e atrasam o crescimento econômico e tecnológico do país.

\section{REFERENCIAS}

AREND, M.; CARIO, S. A. F. Desenvolvimento e desequilíbrio industrial no Rio Grande do Sul: uma análise secular evolucionária. Economia e Sociedade, v. 19, n.2 (39), p.381-420, 2010.

AREND, M.; CARIO, S. A. F.; ENDERLE, R.. Instituições, inovações e desenvolvimento econômico. Pesquisa \& Debate, v. 23, n. 1 (41), p.110-133, 2012.

AZEVEDO, P.. A interação UFSC e Petrobrás para o desenvolvimento inovativo sob ótica institucionalista - evolucionária. Tese (Doutorado) Programa de Pósgraduação em Administração, Universidade Federal de Santa Catarina, SC. 2016.

BORGES, William. A trajetória tecnológica das máquinas e equipamentos agrícola no Brasil: uma análise a partir da integração teórica-analítica das abordagens evolucionária e institucionalista. Tese (Doutorado) Programa de Pósgraduação em Administração, Universidade Federal de Santa Catarina, SC. 2016.

CASSIOLATO, J. E.; CAMPOS, R. R.; STALLIVIERI, F.. Processos de aprendizagem e inovação em setores tradicionais: Os arranjos produtivos locais de confecções no Brasil. EconomiA, Brasília (DF), v.7, n.3, p.477-502, set/dez. 2007.

CAVALCANTE, C. M.. Commons e Veblen: da existência de uma unidade conceitual no âmbito do institucionalismo americano. Revista Ciências Sociais em Perspectiva, v. 18, n. 34, p. 56-72, 2019.

COASE, R. H. The Institutional Structure of Production. The American Economic Review, Vol. 82, No. 4, pp. 713-719, 1992.

COMMONS, J. R. Institutional Economics. American Economic Review, vol.21, p.648-657, 1931.

CONCEIÇÃO, O. A. C. Além da transação: uma comparação do pensamento dos institucionalistas com os evolucionários e pós-keynesianos. Revista Economia, Brasília, v. 8, n. 3, p. 621-642, 2008 a.

CONCEIÇÃO, O. A. C. A dimensão institucional do processo de crescimento econômico: inovações e mudanças institucionais, rotinas e tecnologia social. Economia e Sociedade, v. 17, n. 1, p. 85-108, 2008b. 
CONCEIÇÃO, O. A. C. Há compatibilidade entre a" tecnologia social" de Nelson e a" causalidade vebleniana" de Hodgson?. Brazilian Journal of Political Economy, v. 32, n. 1, p. 109-127, 2012.

CONCEIÇÃO, O. A. C. Instituições, crescimento e mudança na ótica institucionalista. Fundação de Economia e Estatística Siegfried Emanuel Heuser, 2002.

CONCEIÇÃO, O.A. C. Tecnologia social e instituições: uma relação conceitual simbiótica. Economia \& Tecnologia. Ano 5, v. 16, p. 99-108, jan/mar. 2009.

DOSI, G.. Sources, procedures, and microeconomic effects of innovation. Journal of economic literature, vol. 26, n.3, p. 1120-1171, 1988.

EDQUIST, C.. Systems of Innovation: perspectives and challenges. In: FARGERBERG, J.; MOWERY, D.; NELSON , R. (eds). The Oxford Handbook of Innovation. Reino Unido: Oxford University Press, p. 182-205, 2006.

FAGERBERG, J.; VERSPAGEN, B.. Innovation, growth and economic development: have the conditions for catch-up changed?. International Journal of Technological Learning, Innovation and Development, v. 1, n. 1, p. 13-33, 2007.

FAULKNER, W.; SENKER, J.. Making sense of diversity: public-private sector research linkage in three technologies. Research Policy, v. 23, n.6, p. 673-695, 1994.

FELIPE, E. S.. As instituições e os neo-schumpeterianos: a noção de aprendizado a partir do pilar cognitivo das instituições. Pesquisa \& Debate, v. 19, n. 1 (33), p.15-32, jan-jun. 2008.

FERNANDES, A. C.; CAMPELLO DE SOUZA, B.; STAMFORD DA SILVA, A.; SUZIGAN, W.; CHAVES, C. V.; ALBUQUERQUE, E. Academy-industry links in Brazil: evidence about channels and benefits for firms and researchers. Science and Public Policy, v. 37, n.7, p. 485-498, 2010.

FERNANDES, A. C.; LIMA, J. P. R. Labirintos da interação universidade-empresa: estudos de caso dos setores elétrico e sucroalcooleiro em Pernambuco. In: GARCIA, R.; RAPINI, M.; CARIO, S. Experiências de interação universidade-empresa no Brasil. Belo Horizonte: Editora Cedeplar, 2018.

FREEMAN, Cristopher. Japan: a new national system of innovation? In: DOSI, G., FREEMAN, C., NELSON, R., SILVERBERG, G., SOETE, L. (Eds.), Technical Change and Economic Theory. Pinter Publishers, London, 1988.

HODGSON, Geoffrey M. Economics in the Shadows of Darwin and Marx: Essays on Institutional and Evolutionary Themes, Edward Elgar, Cheltenham. 2006.

HODGSON, Geoffrey M. Institutional economics: surveying the 'old' and the 'new'. Metroeconomica, v. 44, n. 1, p. 1-28, 1993.

HODGSON, Geoffrey. M. El Enfoque de la economia institucional. Revista Análisis Económico, v. 16, n.33, p.3-41, 2ํㅗ sem. 2001.

HODGSON, Geoffrey M. Evolution and institutions: On Evolutionary economics and the evolution of economics. Edward Elgar Pub, 1999. 
KRETZER, J.. Sistemas de inovação: as contribuições das abordagens nacionais e regionais ou locais. Ensaios FEE, v. 30, n. 2, p. 863-892, 2009.

LEMOS, D. da C.. A interação universidade-empresa para o desenvolvimento inovativo sob a perspectiva institucionalista-evolucionária: uma análise a partir do sistema de ensino superior em Santa Catarina. Tese (Doutorado) Programa de pós-graduação em Administração, Universidade Federal de Santa Catarina, SC. 2013.

LIST, F.. The National System of Political Economy. Translation by Sampson S. Lloyd, with an Introduction by J. Shield Nicholson). London: Longmans, Green and Co., 1909.

LUNDVALL, B.. National innovation systems-analytical concept and development tool. Industry and innovation , v.14, n.1, 95-119, 2007.

LUNDVALL, B..; JOHNSON, B.; ANDERSEN, E. S.; DALUM, B. National systems of production, innovation and competence building. Research policy, v.31, n.2 , p. 213231, 2002.

MAZZOLENI, R.; NELSON, R. R. The roles of research at universities and public labs in economic catch-up. LEM Working Paper Series, 2005.

MITCHELL, W. The rationality of economic activity: II. The Journal of Political Economy, v. 18, n. 3, p.197-216, mar. 1910b.

MONASTERIO, L. M. Guia para Veblen: um estudo acerca da economia evolucionária. Pelotas: EDUFPEL, 1998.

NELSON, R. R; SAMPAT, B. N. Las instituciones como factor que regula el desempeño económico. Revista de economia institucional, v. 3, n. 5, p. 18-51, 2001.

NELSON, R. R. National Innovation Systems: It Is. In: Regional Innovation and Global. Routledge, p.19-34, 2013.

NELSON, R. R. Recent Evolutionary Theorizing About Economic Change. Journal of Economic Literature, v. 33, p. 48-90, march 1995.

NELSON, R. R. What enables rapid economic progress: What are the needed institutions? Research Policy, v. 37, n. 1, p. 1-11, 2008.

NELSON, R. R. What makes an economy productive and progressive? What are the needed institutions?. LEM Working Paper Series, 2006.

NELSON, R. R.; NELSON, K.. Technology, institutions, and innovation systems. Research policy, v. 31, n. 2, p. 265-272, 2002.

NELSON, R. R.; WINTER, S. G. An Evolutionary Theory of Economic Change. Harvard University Press, Cambridge. 1982.

NELSON, R. R.; WINTER, S. G. Uma teoria evolucionária da mudança econômica. Campinas: Unicamp, 2005.

NELSON, R.. The challenge of building an effective innovation system for catchup. Oxford Development Studies, v. 32, n. 3, p. 365-374, 2004. 
NEUBERGER, D.e. Capacitações tecnológicas e mudanças institucionais na indústria farmoquímica brasileira. Tese (Doutorado) Programa de Pós-graduação em Economia, Universidade Federal de Santa Catarina, SC. 2019.

NIOSI, J.. National systems of innovations are "x-efficient"(and x-effective): Why some are slow learners. Research policy, v. 31, n. 2, p. 291-302, 2002.

NORTH, D. C. Institutions. Journal of Economics Perspectives, v. 5, n.1, p.97-112, winter, 1991.

NORTH, D. C. Understanding the process of economic change. Princeton and Oxford: Princeton University Press, 2005.

PARANHOS, J.; PERIN, F. S. Relacionamento universidade-empresa no setor farmacêutico: duas pesquisas comparadas. In: GARCIA, R.; RAPINI, M.; CARIO, S. Experiências de interação universidade-empresa no Brasil. Belo Horizonte: Editora Cedeplar, 2018.

PEREIRA, A. J.; DATHEIN, R.. Processo de aprendizado, acumulação de conhecimento e sistemas de inovação: a "co-evolução das tecnologias físicas e sociais" como fonte de desenvolvimento econômico. Revista Brasileira de Inovação, v.11, n.1, p.137-166, jan/jun. 2012.

PONDÉ, J. L.. Instituições e mudança institucional: uma abordagem schumpeteriana. Revista Economia, v. 6, n. 1, p. 119-160, 2005.

SAMUELS, W. J. The present state of institutional economics. Cambridge Journal of Economics, v. 19, n. 4, p. 569-590, 1995.

SCHUMPETER, J.. A teoria do desenvolvimento econômico. São Paulo: Ed. Abril Cultural, 1982.

SCOTT, R. W. Institutions and organizations: Ideas and interests. Sage, 2008.

SIMON, H. A. The architecture of complexity. Proceedings of the American Philosophical Society, v.106, p.467-482, 1962.

SUZIGAN, W.; FURTADO, J.. Instituições e políticas industriais e tecnológicas: reflexões a partir da experiência brasileira. Estudos Econômicos (São Paulo), v. 40, n. 1, p. 7-41, 2010.

TIGRE, P. B. Gestão da inovação: A economia da tecnologia no Brasil. Rio de Janeiro: Elsevier, 2006.

VEBLEN, T.. Why is Economics not an Evolutionary Science. The Place of Science in Modern Civilization and Other Essays. New York: Russel \& Russel, 1961[1898]. 